\title{
CONSTITUCIONALIDAD DEL NUEVO PROCESO INMEDIATO
}

\author{
ALFREDOG. ARAYA VEGA*
}

\begin{abstract}
Resumen
El nuevo proceso inmediato pretende dar una solución normativa a los problemas de inseguridad ciudadana percibidos en el Perú. Se propone una atención diferenciada y expedita para los delitos cometidos en flagrancia y las delincuencias de mayor incidencia: omisión de asistencia familiar y conducción en estado de ebriedad. El estudio de este nuevo procedimiento debe abarcar las principales críticas, hasta una ponderación de constitucionalidad.
\end{abstract}

Palabras clave: Seguridad ciudadana, plan piloto, flagrancia, proceso inmediato, constitucionalidad.

\begin{abstract}
The new process aims to provide an immediate solution to regulatory problems of citizen insecurity perceived in Perú. A differentiated and prompt attention for crimes committed in flagrancy and the increase of the delinquencies incidence, omission of family support and drunk driving is proposed.
\end{abstract}

* Juez superior del Tribunal Penal de Flagrancias de San José - Costa Rica. Profesor universitario en materia penal y procesal penal. Doctor Honoris Causa, Universidad de Ciencias Jurídicas, México. Amicus Curiae II Pleno Jurisdiccional en Materia Procesal Penal - Discusión proceso inmediato y otros-, Lima 2016. Bachiller, licenciado y magíster en Derecho de la Universidad de Costa Rica. Doctorando en Derecho Penal de la Escuela Libre de Derecho. Doctorando en Estudios de la Sociedad y la Cultura de la Universidad de Costa Rica. Más de cincuenta conferencias internacionales en diferentes países de Latinoamérica. Más de cien cursos de capacitación nacional e internacional, Autor de más de cincuenta artículos en materia penal en revistas especializadas. Autor del libro: La prisión preventiva desde la perspectiva constitucional, dogmática y del control de convencionalidad, Lima, 2014; libro presentado en el Colegio de Abogados del Callao-Lima; libro presentado en el Colegio de Abogados de Morelos-México. Autor del libro: El delito en flagrancia. Análisis y propuesta de nuevo proceso especial. Lima, 2014, presentado en la Corte Suprema de Justicia. Lima, noviembre de 2014; presentado en la Fiscalía General de la República, Tegucigalpa, Honduras, Noviembre de 2014, Reconocimientos: Miembro honorario del Colegio de Abogados Tacna, Lima, Ica, Cusco, Callao en Perú. Miembro honorario del Colegio de Abogados y de la Asociación de Abogados Penalistas en Morelos-México. Profesor universitario en Costa Rica en las universidades Hispanoamericana, Nacional, Internacional de las Américas y Autónoma de Monterrey. Profesor honorario de las universidades Sergio Bernales, César Vallejo y Peruana de los Andes en Perú y del Instituto de Enseñanza de Ciencias Jurídicas, Criminológicas, Sociales y Políticas ITESIS. Profesor agregado a la Revista Digital Pensamiento Penal Argentino, encargado de capacitaciones virtuales de temas varios en materia penal. Visitante ilustre de las ciudades de Tacna, Cusco, Ica y Lima en Perú. 
The study of this new procedure should cover the main criticism, to a weighting of constitutionality.

Keywords: Citizen security, pilot plan, flagrancia, immediate process, constitutionality.

\section{Sumario}

1.- Introducción. 2.- Plan Piloto y Decreto 1194. 2.1- Constitucionalidad.

\section{Introducción}

La justicia, como valor supremo, concibe la obligación del Estado de brindarla con los más altos estándares de calidad, es decir, en un plazo razonable y de manera cercana al hecho. Debe superarse el adagio popular de que la justicia es lenta pero segura, por cuanto se ha demostrado que la ineficiencia y la ineficacia estatales han generado una alarma social de inseguridad y reacciones populares de ejercicio desmedido de violencia no institucional mediante los llamados linchamientos públicos de justicia callejera, propiciados por la irresponsable campaña de redes sociales y medios de comunicación de Chapa tu choro. Los estándares de la justicia democrática se fundan en un sistema eficiente, eficaz, responsable, conforme a la ley, de justicia pronta y cumplida y dentro de un plazo razonable.

La Corte Interamericana de Derechos Humanos ha establecido que el plazo razonable de juzgamientos está correlacionado, entre otros aspectos, con la complejidad del asunto. Por ello, desde ya conviene establecer que deben efectuarse abordajes distintos para delitos de mayor y menor gravedad y actos investigativos.

No han sido pocos los Estados que han impulsado desde el Ministerio Público la creación de oficinas especializadas según los tipos de delincuencia ${ }^{1} \mathrm{o}$, incluso, el nivel de complejidad investigativa, para diferenciar entre delitos complejos y delitos de pronta respuesta. El establecimiento de fiscalías especializadas en delitos comunes, tradicionales o de trámite rápido potencia la eficiencia y eficacia estatal desde el órgano persecutor (Ministerio Público), el cual, mediante políticas de persecución criminal, optimiza los recursos humanos, técnicos, tecnológicos y materiales con que cuenta para responder de inmediato ante las delincuencias.

Sin embargo, la experiencia latinoamericana nos ha mostrado algo distinto en el ámbito jurisdiccional: una justicia lenta, retardada, desigual, altamente burocrática, formalista. La mora judicial bajo esos estándares de ineficiencia e ineficacia ha empezado a

1 Delitos contra la propiedad, delitos económicos, corrupción, tributarios, ambientales, fraudes etc. 
carcomer la institucionalidad y, con ello, se produce un aumento sostenido de la delincuencia y la desconfianza social.

En nuestro criterio, la primera gran respuesta que debe brindarse es un tratamiento judicial diverso a las delincuencias, como lo realiza el Ministerio Público, con el fin de no entremezclar asuntos, sino atenderlos de manera diferenciada y preferente. En resumen, la primera respuesta a la tardanza judicial y a los altos porcentajes de presos sin condena es contar con despachos y jueces especializados, de modo que se puedan atender de forma urgente y expedita los asuntos. En esta línea de pensamiento surge el proceso expedito para delitos en flagrancia, el cual incluye: primero, responder a una criminalidad llamada tradicional ${ }^{2}$, que afecta gravemente a la sociedad en su día a día, compuesta en su mayoría por asuntos de simple y sencilla resolución en virtud de la poca o ninguna actuación investigativa; segundo: razón, eliminando prácticas dilatorias o realización de diligencias innecesarias; tercero: logrando una vinculación importante con los procesos de todos los intervinientes, sean víctimas, testigos o imputados; cuarto: suprimiendo la llamada puerta giratoria, mecanismo en el cual la persona investigada ingresa al sistema pero sale de inmediato sin lograrse de manera suficiente su vinculación con el proceso; quinto: mediante la optimización de los recursos con que se cuenta, tanto humanos como tecnológicos, favoreciendo el uso de las plataformas de notificaciones electrónicas, audiencias videograbadas, resoluciones orales en audiencia y las llamadas audiencias versátiles o multipropósitos.

Dentro de las modalidades de comisión de hechos delictivos, la flagrancia concibe, desde su propia naturaleza jurídica, el hallazgo en el acto de elementos de prueba importantes sobre la participación criminal, con los cuales las investigaciones del hecho se tornan reducidas o nulas. Así, es probable que se cuente con la víctima, testigos, evidencia, instrumentos e imputado. Si se lograra presentar de inmediato ante el Ministerio Público, nos encontraríamos ante una investigación terminada o altamente adelantada.

Por eso se ha escogido la flagrancia delictiva y delitos de mayor incidencia criminal en el Perú como especial para establecer un procedimiento expedito, pues, al contar con ese acervo probatorio desde el primer momento, la resolución se prevé como inmediata. $\mathrm{Si}$, conjuntamente con ello, tuviéramos una fiscalía especializada para estas delincuencias, de modo que exista una reacción inmediata al hecho y una atención privilegiada a policías, víctimas e imputado, los tiempos de espera se reducirían en gran medida.

Ahora bien, el proceso, visto desde el punto de vista sistemático, sería óptimo si, además de un protocolo policial de flagrancia de entrega inmediata al Ministerio Público,

2 Delitos contra la propiedad, contra la seguridad común, o infracciones a leyes especiales como violencia de género, entre otros muchos. 
contáramos con un defensor especializado en delitos en flagrancia y juzgadores abocados de forma exclusiva, o al menos especializada, en las distintas etapas del proceso penal Este es, precisamente, el modelo creado en diversos sitios y digno de seguir.

En la tradición europeo-continental, se ha optado por crear un proceso especial, diferente al ordinario, por lo cual el Ministerio Público puede escoger y atender de manera diferenciada y expedita los asuntos. En algunos sobresale la existencia del saltum procesal, por lo que se suprime la etapa intermedia y se realiza el juicio luego de superada la etapa mínima de investigación. En latitudes latinoamericanas, la experiencia ha sido diversa; países como Argentina, Chile, Ecuador, Costa Rica, El Salvador, Honduras, pese a tener una influencia romano-germánica y contar con esos procesos especiales, se ha introducido un nuevo procedimiento especial, se ha modificado el proceso originario y se ha elegido un proceso sistemático de conexión entre instituciones. Se han potenciado procesos especiales con una duración máxima de un mes y, mediante la atención privilegiada de estos asuntos sencillos de fácil resolución, se ha logrado dar una respuesta social ante las delincuencias de mayor lesión social.

De acuerdo con algunos estudios latinoamericanos, la constante demuestra que los delitos contra la propiedad representan un $60 \%$ de los casos tramitados, y el $80 \%$ de estos se atiende de forma expedita, mismas estadísticas como veremos que ocurre con el proceso inmediato peruano.

De este modo, la introducción del Decreto Legislativo $\mathrm{N}^{\mathrm{0}} 1194$, el cual modifica el proceso especial inmediato, no solo no resulta novedoso en el ámbito latinoamericano, sino que es una coherencia y actualización normativa frente a problemas comunes y nominativos de las sociedades.

\section{Plan Piloto y Decreto Legislativo No 1194}

Existen dos mecanismos para atender los delitos en flagrancia: el primero mediante el establecimiento de un proceso ordinario y el segundo incoando un proceso especial inmediato. Mediante publicación del diario oficial El Peruano de fecha 15 de julio de 2015, se estableció a partir del 1 de agosto de 2015 entraría en vigencia un plan piloto para la implementación de órganos jurisdiccionales de flagrancia delictiva en el distrito judicial de Tumbes, Resolución Administrativa $\mathrm{N}^{\circ}$ 231-2015-CE-PJ. Este nuevo proceso sería cumplido conforme a la misma normativa procesal vigente del proceso inmediato, su finalidad está basada en brindar una respuesta más eficiente y eficaz de la justicia, mediante el establecimiento de despachos judiciales dedicados a la tramitación especial de delitos en flagrancia delictiva en sus diferentes etapas. 
Este plan piloto tuvo una vigencia sumamente reducida, pues en el Decreto Legislativo N¹194, publicado en el diario El Peruano del 30 de agosto de 2015, se modificó el proceso inmediato y se crea un nuevo procedimiento para delitos en flagrancia y se le adjuntan las delincuencias de conducción en estado de ebriedad y omisión al deber alimentario, el cual entró en vigencia para todo el Perú desde el 1 de diciembre de 2015. Según las estadísticas de funcionamiento del plan piloto en el distrito judicial de Tumbes, no tuvo los efectos esperados, ya que el Ministerio Público hizo poco uso de los instrumentos creados ${ }^{3}$, y justificó su falta de incoación en la ausencia de laboratorios de criminalística. Finalmente el proceso inmediato dio inicio en todo el país y al cabo de cien días se han atendido casi diez mil causas con resultados exitosos. Conforme se advirtió en el Decreto Legislativo $N^{\circ} 1194$, se da vigencia a un nuevo procedimiento establecido en los artículo 446 a 448 del Código Procesal Penal.

\subsection{Constitucionalidad}

$\mathrm{Al}$ establecimiento de un plan piloto y nuevo proceso inmediato se le pueden endilgar varias críticas y cuestionamientos sobre su constitucionalidad para considerarla contraria a un Estado de derecho, a las garantías de los procesados. Aspectos que procedemos a dar respuesta.

\section{a) Ampliación de la flagrancia a 24 horas}

En el año 2007 (22 de julio del 2007) el Poder Ejecutivo autorizado mediante delegación de la Ley No 29009 emitió los Decretos Legislativos No 983 y Nº 989 (Fortalecimiento lucha contra el crimen organizado), que modificó la Ley $\mathrm{N}^{\circ}$ 27934 y el artículo 259 del NCPPP; estableciendo en su artículo 4 una nueva definición de hecho flagrante, de esta forma: "Detención en flagrancia: A los efectos de la presente Ley, se considera que existe flagrancia cuando el sujeto agente es descubierto en la realización del hecho punible o acaba de cometerlo o cuando: a) $\mathrm{Ha}$ huido y ha sido identificado inmediatamente después de la perpetración del hecho punible, sea por el agraviado, o por otra persona que haya presenciado el hecho, o por medio audiovisual o análogo que haya registrado imágenes de este y, es encontrado dentro de las veinticuatro (24) horas de producido el hecho punible. b) Es encontrado dentro de las veinticuatro (24) horas, después de la perpetración del hecho punible con efectos o instrumentos procedentes de aquel, o que hubieran sido empleados para cometerlo, o con señales en sí mismo o en su vestido que indiquen su probable autoría o participación en ese hecho delictuoso".

3 En un mes y medio, solo se atendieron ocho causas penales, de las cuales dos fueron conducciones en estado de ebriedad, tres robos, dos hurtos y una tenencia de armas. 
Cómo vemos se realizó a través de esta reforma una ampliación del presupuesto de la flagrancia sobre la actualidad del hecho delictivo y el requerimiento de inmediatez sostenido por el Tribunal Constitucional del 2006 (TC. 2617-2006); motivo por el cual resultó cuestionada su aplicación y se determinó que hubo sustracción en la materia (TC. 1958-2008 y 1871-2009).

De igual forma mediante Ley № 29569 Ley que modifica el artículo 259 del Código Procesal Penal: se establece en el artículo primero la reforma "Artículo 259.- Detención Policial: La Policía Nacional del Perú detiene, sin mandato judicial, a quién sorprenda en flagrante delito. Existe flagrancia cuándo: 1. El agente es descubierto en la realización del hecho punible 2. El agente acaba de cometer el hecho punible y es descubierto 3. El agente ha huido y ha sido identificado durante o inmediatamente después de la perpetración del hecho punible, sea por el agraviado o por otra persona que haya presenciado el hecho, o por medio audiovisual, dispositivos o equipos con cuya tecnología se haya registrado su imagen, y es encontrado dentro de las veinticuatro (24) horas de producido el hecho punible. 4. El agente es encontrado dentro de las veinticuatro (24) horas después de la perpetración del delito con efectos o instrumentos procedentes de aquel o que hubieren sido empleados para cometerlo o con señales en sí mismo o en su vestido que indiquen su probable autoría o participación en el hecho delictuoso. Como vemos se vuelve nuevamente a lo descrito en los decretos y la ampliación de los supuestos de flagrancia (Decretos Legislativos $\mathrm{N}^{\circ} 983$ y N $\mathrm{N}^{\circ}$ 989), sin embargo, estos no contemplan de modo suficiente y adecuado los requisitos de percepción directa de la comisión del delito, inmediatez temporal e inmediatez personal requeridos por el Tribunal Constitucional en otrora. Esta indebida ampliación de los supuestos fácticos de flagrancia supone nuevas condiciones mediante las cuales se vulnera el derecho fundamental de la libertad y de detención sin previa orden judicial.

Será hasta el 2010; cuando se conoce la sentencia STC 12-2008 donde el máximo órgano constitucional sostuvo que hubo sustracción por la materia; sin embargo, para ese momento ya se encontraba en vigencia la Ley $\mathrm{N}^{0} 29372$ del año 2009 que había vuelto a la definición dogmática de flagrancia.

Es por ello que mediante la Ley $\mathrm{N}^{\circ} 29372$, publicada el 9 de junio de 2009, se modificó nuevamente el artículo 259 del Código Procesal Penal del 2004, estableciendo: "Existe flagrancia cuando la realización de un hecho punible es actual y en esa circunstancia, el autor es descubierto o cuando es perseguido y capturado inmediatamente después de haber realizado el acto punible o cuando es sorprendido con objetos o huellas que revelan que acaba de ejecutarlo".

Esta norma que fue validada como constitucional y conforme a su propia jurisprudencia al sostener el Tribunal Constitucional en la sentencia STC 12- 
2008. “En relación al artículo $3^{\circ}$ del Decreto Legislativo $N^{0} 983$ que modifica el artículo 259 del Nuevo Código Procesal Penal, que regulaba la flagrancia, se ha producido la sustracción de la materia porque la Ley $N^{0} 29372$ ha definido la flagrancia en términos, ahora sí, acordes con la jurisprudencia del Tribunal Constitucional (sentencias $N^{0} 1958$ 2008-PHC; $N^{o}$ 5423-2008-PHC y No 1871-2009-PHC), y no como se proponía en la legislación modificada, extendiendo dicha situación a las 24 horas posteriores a la comisión del delito".

Ya en el año 2010 se da una nueva reforma de ley al artículo 259 del Código Procesal penal, Ley $\mathrm{N}^{\circ} 20569$, momento en el cual se vuelve a la descripción sostenida en los Decretos Legislativos No 983 y No 989 (mismo que el Tribunal Constitucional había determinado como contrario a su jurisprudencia STC 122008).

De este modo, esta nueva ley y aún vigente impone: Artículo $1^{\circ}$ de la Ley $N^{o}$ 29569 del 25 de agosto del 2010 «Artículo 259 Detención policial: La Policía Nacional del Perú, detiene, sin mandato judicial, a quien sorprenda en flagrante delito. Existe flagrancia cuando: 1. El agente es descubierto en la realización del hecho punible. 2. El agente acaba de cometer el hecho punible y es descubierto. 3. El agente ha huido y ha sido identificado durante o inmediatamente después de la perpetración del hecho punible, sea por el agraviado o por otra persona que haya presenciado el hecho, o por medio audiovisual, dispositivos o equipos con cuya tecnología se haya registrado su imagen, y es encontrado dentro de las veinticuatro horas de producido el hecho punible. 4- El agente es encontrado dentro de las veinticuatro horas después de la perpetración del delito con efectos o instrumentos procedentes de aquel o que hubieren sido empleados para cometerlo o con señales en sí mismo o en su vestido que indiquen su probable autoría o participación en el hecho delictuoso».

A la fecha esa es la definición vigente y no ha existido cuestionamiento constitucional sobre el particular. A nuestro criterio, la determinación del presupuesto flagrante de los hechos resulta de suma importancia en el ordenamiento jurídico, sobre todo de cara al respeto de los derechos humanos y el principio base pro libértate. Es claro que para la construcción normativa de un hecho flagrante se requiere de una inmediatez personal que supone que el delincuente se encuentre en el lugar de los hechos o muy próximo a ellos, así como la temporal, entendida como el momento de detención versus el hecho delictivo. De esta forma, la naturaleza procesal de la flagrancia actual en los supuestos de flagrancia clásica, cuasiflagrancia y flagrancia presunta resulta más acorde con la línea teórica dogmática del instituto. Figuras que se caracterizan, como ya se dijo, por la presencia de inmediatez temporal, personal o espacial y proporcionalidad, así como urgencia. 
Consideramos que debe volverse a la postura doctrinal de flagrancia en sentido estricto, cuasiflagrancia y flagrancia presunta. La definición amplificada de flagrancia establecida no es correspondiente con los supuestos de inmediatez necesaria para su establecimiento y establece presupuestos amplificados a la excepción constitucional restrictiva dada de detención sin orden previa judicial, lo cual sin duda resulta improcedente en un Estado Democrático de Derecho y resulta insatisfactorio con los lineamientos base de la Corte Interamericana de Derechos Humanos. Esta misma línea de pensamiento parece que es la seguida por el Tribunal Constitucional 17572011-PHC/TC, al requerir nuevamente la existencia de los factores de inmediatez personal y temporal para la configuración delictual flagrante.

b) Tribunales y jueces especiales Los tribunales de flagrancia se instituyeron sin marco legal ni mediante un procedimiento constitucional, por lo cual resultan contrarios a la Constitución y lesionan el debido proceso y el derecho internacional de los derechos humanos (art. 8.1. del Pacto de San José)

El artículo 104 de la Constitución Política señala: El Congreso puede delegar en el Poder Ejecutivo la facultad de legislar, mediante decretos legislativos, sobre la materia específica y por el plazo establecidos en la ley autoritativa.

El proceso inmediato se estableció mediante la delegación realizada por el Poder Legislativo al Ejecutivo en la Ley $\mathrm{N}^{0} 30336$ que le permitió legislar en temas de seguridad ciudadana y crimen organizado por el plazo de noventa días. De este modo, el 30 de agosto del 2015 mediante el Decreto Legislativo ${ }^{\circ}$ 1194 se modificó la Sección I del Libro V del Código Procesal Penal.

La democracia se rige bajo el eje de la división de poderes, sistema de frenos y contrapesos. Las potestades legislativas en un sistema democrático son dadas a los diputados o congresistas, quienes en virtud de las decisiones dadas por el pueblo en las urnas los han investido de la autoridad suficiente para imponer las reglas de comportamiento y normas de cumplimiento. Por ello cualquier injerencia entre poderes o componendas resultan lesivos a las democracias.

El procedimiento de delegación es una muestra inequívoca de incapacidad del legislador de resolver los temas de inseguridad ciudadana, desconoció los mecanismos legales ordinarios de legislación como lo son: conocer de iniciativas populares mediante referendums, recomendaciones del Poder Judicial que pueden ser tomados por legisladores para construir propuestas de proyectos de ley o incluso las potestades del gobernante que a través de 
proyectos del Ley; vincula al Poder Ejecutivo al legislativo para conocer de propuestas de modo extraordinario.

En ese contexto, la delegación dada mediante la Ley $N^{\circ} 30336$, si encuentra sustento constitucional en el artículo 104 de la Constitución Política Peruana, promocionado por la excepcionalidad y urgencia dada en el momento histórico que ocurría de linchamientos públicos y desprestigio institucional (chapa tu choro y déjalo paralítico).

c) Violación al principio de autonomía del Ministerio Público al establecerse la incoación del proceso inmediato como obligación y no como potestad.

Se critica que a través de este nuevo procedimiento, se pretende obligar al Ministerio Público a instaurar el procedimiento inmediato en la totalidad de las detenciones en flagrancia, en los delitos de omisión de asistencia familiar y en conducciones en estado de ebriedad. El que medien criterios de racionalidad, eficiencia, eficacia o incluso decisiones institucionales producto de prácticas culturales forenses; no hacen per se que el proceso sea constitucional en sentido estricto; sino que debe tamizarse a través de los principios constitucionales y normas supraconstitucionales su legitimidad.

Visto el artículo 446 del CPP de forma aislada, cuando se modifica el puede, por el debe, hace que esa norma sea inconstitucional por violación al principio de autonomía del Ministerio Público (artículos 60 CPP y 158 y 159 de la Constitución Política), por cuanto hay una interferencia indebida y nociva para el ejercicio de la acción penal, estrategias investigativas y resultados de los procesos penales.

Sin embargo, si se observa con atención toda la reforma establecida, vemos que el proceso inmediato no es inconstitucional ni tampoco lesivo para el Ministerio Público en el ejercicio de su acción penal, ya que el artículo 446.2 establece la excepción en virtud de la complejidad de los casos. Esta excepción no es ociosa, sino que responde a la lógica de un proceso respetuoso de las garantías y los derechos de defensa de todas las partes procesales. De este modo, en la medida que los casos no sean de simple y sencilla tramitación o resolución -simplicidad procesal-, será el proceso común la vía adecuada para que los casos sean resueltos.

La pregunta necesaria a formularse es qué debemos entender por complejidad. La solución es variada.

Número de intervinientes: Puede estar referida a la multiplicidad de personas intervinientes en el proceso como lo son imputados, ofendidos, abogados u 
hechos delictuosos atribuidos. En el caso de los imputados debe recordarse que se requiere una imputación suficiente para cada uno de ellos y prueba que lo acredite. Igual puede suceder que se acuse a una sola persona de varios hechos criminales. Por ejemplo una persona que en recorrido ha cometido varias delincuencias, es perseguido y detenido en el último de ellos.

Obtención fuentes, medios y datos de prueba: Referido a las diferentes gestiones del Ministerio Público o incluso de la propia defensa tendientes a la obtención de prueba; desde su ubicación, fijación, recolección, preservación y presentación; así como también la ponderación de las dificultades que puedan presentarse sea por el tiempo como a la realización de pruebas sobre estas. También estaría cubierto supuestos de grupos delictuales organizados o cuya delincuencia requiere de multiplicidad de actividades investigativas o que se deduzca razonablemente de estas nuevas diligencias, por ejemplo en delitos de varias escenas del delito.

Sometimiento otros responsables: Se trata de supuestos dónde se requieren mayor cantidad de actos investigativos tendientes a la ubicación de corresponsables en la acción delictiva y de los cuales se este realizando actos de investigación directos a su detención producto de su individualización indubitable, personas que no fueron detenidas en flagrancia y cuya conducta no puede permanecer en la impunidad.

Gravedad del hecho imputado: Los delitos graves exigen una mayor rigurosidad probatoria y analítica de la prueba, por esto su esclarecimiento, actividad probatoria, delimitación conforme a la teoría del delito y juicio de reproche es más exigente. El acerbo probatorio es mayor a efecto de cumplir con los principios constitucionales de quebrantamiento de inocencia y proporcionalidad. Dicho esto, el órgano requirente deberá presentar los delitos graves ante el proceso común, esto por cuanto la exigencia probatoria y de motivación es mucho mayor, desde la demostración del hecho, como el análisis pormenoralizado de las eximentes, agravantes, atenuantes del hecho y de la pena. Para determinar la gravedad debe acudirse necesariamente a los extremos punitivos legislativamente creados, importancia o afectación al bien jurídico tutelado, gravedad de los hechos, número de víctimas. En resumen, de acuerdo con la dosimetría penal de cada país, debe establecerse que asuntos deben y no presentarse mediante este procedimiento simplificado.

Actividad procesal del interesado: Si bien ya hemos señalado con anterioridad que la obtención de la prueba es un factor esencial, merece especial consideración la actividad procesal propuesta y admitida por pertinencia, 
utilidad, necesidad y conducencia ofrecida por la defensa del imputado o la propia víctima. Este proceso no puede menoscabar las garantías individuales y colectivas previstas en la norma procesal y la Constitución Política.

d) Violación al principio de igualdad: La persona detenida en flagrancia es atendida en un proceso distinto al ordinario, con lo cual se violenta el debido proceso legal y la igualdad de armas respecto a los plazos (el art. 8.1 del Pacto de San José da derecho a ser oído con las debidas garantías).

La existencia de un procedimiento especial no es per se una cuestión discriminatoria y desigual, siempre y cuando exista una base objetiva que requiera efectuar la diferenciación.

El Código Procesal Penal tiene ocho diversos procedimientos especiales (ver Libro V). La atención de delitos en flagrancia pretende atender con más agilidad los asuntos al disminuir los plazos de resolución. Esto se realiza partiendo del presupuesto objetivo de que, desde la propia detención en flagrancia, el ente acusador cuenta con la existencia de elementos de prueba necesarios para su resolución (la existencia de una víctima del hecho, testigos presenciales, decomiso de bienes e instrumentos, etc.).

Cabe resaltar que el plan piloto y ya con la vigencia del Decreto Legislativo $\mathrm{N}^{\mathrm{o}}$ 1194 se procura dar vigencia a un proceso especial en desuso y no es un proceso novísimo. En ese procedimiento, las partes cuentan con todos los tiempos de preparación de la defensa y el ejercicio de garantías judiciales. Contrario a lo criticado, el imputado mantiene intactas sus garantías, pues, lejos de retardarse de manera injustificada el proceso penal (pena de banquillo muchas veces, incluso privado de su libertad), el proceso se resuelve en los plazos legalmente establecidos, con una justicia oportuna. Por último, es falso y contrario a los principios constitucionales que el imputado adquiera un derecho al retraso judicial que genere su impunidad (sea por desinterés de la víctima, por prescripción u otros motivos).

En resumen, el establecimiento de procesos especiales distintos al común no solo son legales sino que además protectores ambos del debido proceso legal y el derecho de defensa. Eso sí, debe mantenerse la vigilancia de suprimir prácticas inconstitucionales que pretendan vulnerarlo, cómo pueden ser invertir principios de inocencia, carga probatoria, legalidad etc.; así como también políticas institucionales del Ministerio Público que pretendan hacer imponer medidas extorsivas para la aceptación de cargos sin que existan la totalidad de elementos de prueba y una imputación concreta determinada. Por último, los jueces al jurar el cumplimiento de la ley y la Constitución son 
garantes del cumplimiento y rigurosidad del derecho de defensa, no debe admitirse prácticas tendenciosas a una justicia express sin contener los medios adecuados, suficientes, acordes y prudentes de una justicia democrática.

e) Derecho de defensa: Se critica que conculca el derecho del imputado a contar con el tiempo y medios adecuados para preparar la defensa (art. 8.1.c. del Pacto de San José).

El derecho de defensa, tanto material como técnica, se encuentra resguardado en el plan piloto y en el Decreto Legislativo $\mathrm{N}^{\mathrm{0}} 1194$. Al imputado se le brindan todas las garantías legales y procesales: se le nombra un defensor, cuenta con los derechos de conocer los cargos, ser oído ante juez, ofrecer pruebas y declarar si es su intención, así como recurrir la sentencia. De igual modo, al respetarse claramente todos los plazos contenidos en el Código Procesal Penal para las distintas etapas, el imputado mantiene incólumes todas las garantías y los tiempos de preparación para ofrecer prueba y constituir su teoría del caso (derecho de defensa técnica y material). Resulta obvio que si los abogados no se prepararan y cumplen con sus deberes, podría generarse deficiencias en la defensa, empero esta es distante al propio procedimiento.

f) Violación del principio de inocencia: Se critica que la sola definición de delincuente en estado de flagrancia violenta el principio de inocencia y se tiene como una presunción de culpabilidad.

La declaratoria de flagrancia se refiere a la consecuente detención por la comisión del hecho criminal, pero no es una referencia a su culpabilidad ni un adelanto de responsabilidad, sino que esta la decreta un tribunal de justicia luego de escuchar toda la prueba en juicio oral y público. Por lo tanto, no pueden confundirse ambos supuestos.

g) Contrario a un Estado de derecho: Se atribuye al procedimiento de flagrancia la disminución de garantías procesales y sustantivas de los imputados.

En nuestro criterio, las nociones de eficacia-eficiencia, por un lado, y las garantías, por el otro, no deben presentarse como dos fuerzas antagónicas o irreconciliables en la investigación criminal. Eficiencia y garantía son dos principios básicos del sistema jurídico que pueden y deben convivir. El desafío consiste en lograr su armonía, y no la prioridad de un modelo en detrimento del otro.

Desde luego, esa búsqueda de eficiencia y eficacia de la Administración de Justicia no puede desbordar el marco de las garantías fundamentales y la 
mejor tradición jurídica asentada en el país. La celeridad procesal debe respetar el debido proceso (incluido el derecho de defensa) y las garantías judiciales reconocidas por nuestro país mediante la Convención Americana de Derechos Humanos ${ }^{4}$. El derecho de todo ciudadano a ser juzgado en un plazo razonable (artículo 8.1 de la Convención Americana de Derechos Humanos ya citado), que constituye un deber del Estado, contiene una doble preocupación: por una parte para el imputado, de conocer con la seguridad jurídica necesaria la resolución del proceso en su contra, con mayor razón si se encuentra privado de su libertad de modo preventivo; pero, además, el ciudadano víctima de un suceso tiene derecho a que el Estado le resuelva de un modo ágil y oportuno el conflicto planteado. Ahora bien, la determinación de los parámetros de razonabilidad para determinar los plazos de resolución no ha sido una labor sencilla. La jurisprudencia ha señalado que determinar la duración de un proceso judicial es facultad del juez, quien debe definir, conforme al caso concreto, cuál es el tiempo razonable, proporcional y necesario para su resolución. Para la Corte Interamericana de Derechos Humanos $^{5}$, el derecho a ser juzgado en un plazo razonable tiene como finalidad impedir que los acusados permanezcan largo tiempo bajo acusación, asegurar que esta se decida prontamente, así como establecer un

4 Convención Americana de Derechos Humanos, art. 8, Garantías Judiciales: 1.Toda persona tiene derecho a ser oída con las debidas garantías y dentro de un plazo razonable, por un juez o tribunal competente, independiente e imparcial, establecido con anterioridad por la ley, en la sustanciación de cualquier acusación penal formulada contra ella, o para la determinación de sus derechos y obligaciones de orden civil, laboral, fiscal o de cualquier otro carácter. 2. Toda persona inculpada de delito tiene derecho a que se presuma su inocencia mientras no se establezca legalmente su culpabilidad. Durante el proceso, toda persona tiene derecho, en plena igualdad, a las siguientes garantías mínimas: a) derecho del inculpado de ser asistido gratuitamente por el traductor o intérprete, si no comprende o no habla el idioma del juzgado o tribunal; $b$ ) comunicación previa y detallada al inculpado de la acusación formulada; c) concesión al inculpado del tiempo y de los medios adecuados para la preparación de su defensa; d) derecho del inculpado de defenderse personalmente o de ser asistido por un defensor de su elección y de comunicarse libre y privadamente con su defensor; e) derecho irrenunciable de ser asistido por un defensor proporcionado por el Estado, remunerado o no según la legislación interna, si el inculpado no se defendiere por sí mismo ni nombrare defensor dentro del plazo establecido por la ley; f) derecho de la defensa de interrogar a los testigos presentes en el tribunal y de obtener la comparecencia, como testigos operitos otras personas que puedan arrojar luz sobre los hechos; $g$ ) derecho a no ser obligado a declarar contra sí mismo ni a declararse culpable, y $h$ ) derecho de recurrir del fallo ante juez o tribunal superior. 3. La confesión del inculpado solamente es válida si es hecha sin coacción de ninguna naturaleza. 4 . El inculpado absuelto por una sentencia firme no podrá ser sometido a nuevo juicio por los mismos hechos. 5. El proceso penal debe ser público, salvo en lo que sea necesario para preservar los intereses de la justicia.

5 Ver, en ese sentido, Corte Interamericana de Derechos Humanos, caso Genie Lacayo vrs. Nicaragua (29 de enero de 1997, considerando 77); caso Suárez Rosero vrs. Ecuador (12 de noviembre de 1997), punto 70 y 72 ; caso López Álvarez vrs. Honduras. Debe recordarse que este mismo principio está contenido en el artículo 6 del Convenio Europeo sobre Salvaguarda de los Derechos del Hombre y las Libertades Fundamentales (suscrito en Roma en 1950), reproducido literalmente por la Convención Americana de Derechos Humanos (suscrita en San José, Costa Rica, en 1969). 
lapso preciso que constituya el límite entre la duración razonable y la prolongación indebida e innecesaria de un proceso. $\mathrm{Al}$ respecto, estableció que, para fijar el plazo razonable mencionado en el artículo 8.1, se deben ponderar las circunstancias concretas de los asuntos: a) complejidad del asunto, b) actividad procesal del interesado y c) conducta de las autoridades judiciales.

Por eso estimamos viable, necesaria y oportuna la fijación de un plazo legal objetivo, taxativo e improrrogable, según las circunstancias objetivas de los hechos. Como ya se ha dicho, los procesos penales donde la detención se realiza en flagrancia y en los supuestos legales establecidos permiten al órgano requirente valorar la pertinencia y utilidad de elementos de prueba, sobre todo para acreditar la autoría de los hechos del imputado. Con ello, el proceso de tramitación y resolución se reduce notablemente respecto a otras sumarias de trámite complejo, donde no se cuenta con detenidos ni circunstancias objetivas de realización del hecho criminal.

La complejidad del asunto fue el factor objetivo considerado para limitar el plazo de resolución de la causa penal, valorando factores de hecho y derecho. La celeridad en la resolución del proceso, sin dilaciones indebidas, es un derecho que importa tanto a la víctima del delito como al imputado. El derecho a un juicio rápido contiene el respeto a los principios de seguridad jurídica, justicia rápida, progresividad y preclusión de etapas, todos los cuales obedecen a la existencia constitucional de respeto a la dignidad humana ${ }^{6}$. El derecho a un juicio rápido, sin dilaciones indebidas o injustificadas, se halla consagrado en el artículo XXV de la Declaración Americana de Derechos Humanos (Bogotá, 1948), 14.3 c del Pacto Internacional de Derechos Civiles y Políticos (1966) y en la Sexta Enmienda a la Constitución de los Estados Unidos de Norteamérica. La desmedida duración del proceso no es un problema menor. No solo debe tratarse por medio de una política criminal integradora, sino que también debe ser abordado y resuelto por el proceso penal, con una respuesta oportuna a los conflictos planteados, de acuerdo con los principios de servicio público y de justicia oportuna.

Coincidimos del todo en cuanto a las funciones del derecho procesal penal (debido proceso legal, respecto de garantías judiciales de partes) y del derecho penal sustancial (subsidiariedad, fragmentariedad, legalidad,

6 La Corte Interamericana de Derechos Humanos, en el caso López Álvarez vs. Honduras (párrafo 128), señaló: "El derecho de acceso a la justicia implica que la solución a la controversia se produzca en tiempo razonable; una demora prolongada puede llegar a constituir, por sí misma, una violación de garantías judiciales". 
derecho penal de acto, lesividad, culpabilidad, proporcionalidad, dignidad humana, entre otras) como parte de un sistema. Ahora bien, las funciones del derecho penal no son solo esas: también debe cumplir una función preventiva general, con el fin de asegurar la paz social y el funcionamiento del derecho como mecanismo resolutorio de conflictos. Esa función debe brindarse oportuna y eficientemente, pues su duración prolongada la hace inoperante y desproporcionada.

Consideramos que solo de esta forma el derecho penal se modernizará de modo adecuado, respetando los principios rectores que originaron su funcionamiento. Recordemos el viejo aforismo: "Justicia retardada es justicia denegada". El debido proceso legal exige respetar las garantías legales y procesales a quien vaya a ser juzgado. Conviene aclarar que, si bien se suprimió la fase intermedia, esta se vio sustituida por la audiencia inicial, donde el imputado cuenta con todos los derechos que antes tenía con la etapa intermedia: conocer de la acusación, objetarla, ofrecer prueba, acogerse a salidas alternas o someterse a un procedimiento especial abreviado.

El principio de imparcialidad y objetividad del juez no se lesiona al decretar la competencia de un proceso especial, pues solo pondera si los hechos investigados por el Ministerio Público cumplen los presupuestos de los artículos 259 y 446 del Código Procesal Penal. Tampoco se lesiona al advertir correcciones en la acusación, porque es un contralor del cumplimiento del principio de legalidad y debido proceso en general y no corrige la acusación. Sobre la publicidad, se señala que la Constitución Política no garantiza al imputado el no ser expuesto públicamente, sino que prohíbe presentarlo como culpable antes de que un juez lo haya declarado como tal. Por último, sobre el derecho a un recurso contra la competencia y medidas cautelares, no existe un derecho irrestricto a la doble instancia. El hecho de establecer o no la posibilidad de plantear recurso de apelación, no violenta el debido proceso, pues el derecho a recurrir, de conformidad con el artículo $2.8 \mathrm{~h}$ de la Convención Americana de Derechos Humanos, está previsto en relación con la sentencia condenatoria y no en relación con todas las resoluciones del proceso, empero la propia ley la tiene prevista. Además, debe ponderarse si el procedimiento expedito resulta lesivo del debido proceso, propiamente en sus principios de intimación, imputación, derecho de audiencia y derecho de defensa en sí. El principio de intimación, como se refirió, proviene del artículo 446 del Código Procesal Penal, cuando se señala al Ministerio Público su deber de instruir al imputado de sus cargos mediante una relación oportuna, expresa, clara y circunstanciada de los hechos y sus consecuencias legales. 
El principio de imputación no se lesiona, porque el Ministerio Público, una vez agotada la fase investigativa, solicitará una audiencia sin formalidades y formulará la acusación conforme al artículo 447 en relación con el artículo 336 del Código Procesal Penal. En esta audiencia, debe describir de manera clara, detallada y precisa el hecho que se acusa, hacer una calificación legal, indicar los fundamentos de derecho de la acusación y concretar la pretensión punitiva, así como ofrecer prueba pertinente para demostrar los hechos acusados.

El derecho de audiencia se refiere al derecho del imputado y su defensor de conocer los actos relevantes del proceso, intervenir en él, en particular hacerse oír por el juez, traer al proceso toda la prueba que consideren oportuna para respaldar su defensa, controlar la actividad de la parte o las partes contrarias y combatir los argumentos y pruebas de cargo. Estos aspectos puede desarrollarlos la defensa del imputado a lo largo del procedimiento expedito, tanto en la fase investigativa como en la audiencia inicial y en la fase de juicio.

Con esto se garantiza el debido proceso, al otorgar a la defensa técnica y material el acceso irrestricto a las pruebas de cargo y la posibilidad de combatirlas, en especial ante el juez en caso de ser citado, además del derecho a un proceso público y el derecho a no ser obligado a declarar en contra de sí mismo.

h) Ausencia de solución ante la seguridad ciudadana Se califica como una ley inconstitucional (ley de emergencia) violatoria de garantías. Se critica que el procedimiento de flagrancia concentra esfuerzos en los mismos casos que el sistema penal procesa en la actualidad, orientados hacia los sectores más vulnerables de la población, que son quienes pueblan las cárceles.

Se señala que, si bien es positivo intentar agilizar el sistema de justicia, las medidas dispuestas no resolverán el problema de fondo en materia de seguridad, porque se apunta solo a algunos delitos y no se dispone nada para atacar otros de mayor gravedad. De igual modo, se indica que sigue ausente una política criminal dirigida a poner freno a los delitos complejos, precisamente los que deberían preocupar a las autoridades y al sistema judicial.

Una de las críticas más fuertes al procedimiento expedito para la atención de los delitos en flagrancia es que per se no determina una disminución de la criminalidad y, por ende, no generará una mayor seguridad ciudadana. 
Estos procedimientos (como el de flagrancias) no deben tener como objetivo único la mejora de la seguridad ciudadana (de modo principal), por tratarse de un aspecto multifactorial, que debe ser resuelto mediante medidas integrales de justicia social (salud, deporte, económicas, financieras, educativas, entre otras) y no solo represivas.

El Estado debe diseñar e implementar políticas nacionales de seguridad para los ciudadanos, basadas en la vigencia institucional (políticas de control social formal) y medios de prevención de la delincuencia (control social informal), acciones que a todas luces son multidimensionales. Debe crear políticas nacionales tendientes a dar preponderancia a los derechos humanos, lo cual se logra por medio de una participación de los ciudadanos en la toma de acciones (visión democrática).

En una sociedad cuyos índices de desigualdad social son marcados, se percibe públicamente que los problemas de seguridad ciudadana provocan un deterioro de la calidad de vida de las personas.

En el Informe nacional sobre desarrollo humano ${ }^{7}$, elaborado por el Programa de Naciones Unidas para el Desarrollo (PNUD), se indica en torno a la inseguridad:

"1. La inseguridad ciudadana no es causada por un solo factor, sino por la convergencia de muchos (...). 2. La inseguridad ciudadana es un obstáculo para el desarrollo humano por cuanto limita las posibilidades individuales de concebir y concretar un proyecto de vida, y erosiona la cooperación social y la vida cívica necesarias para el efecto. 3. Es posible construir una sociedad más segura si se atienden las formas de vulnerabilidad social en que proliferan la violencia y el despojo, y se fortalecen los mecanismos colectivos de protección y la capacidad de las personas para activarlos".

Pero, más allá de la seguridad ciudadana, el Estado debe proporcionar seguridad humana, entendida esta como el conjunto de condiciones básicas y garantías mínimas para el desarrollo humano, o sea, la vigencia de los derechos humanos.

Se afirma que la seguridad ciudadana es una parte vital de la noción, mucho más amplia, de la seguridad humana. Si esta última atiende a formas de vulnerabilidad que comprometen el disfrute de los derechos humanos en general, la seguridad ciudadana se refiere a modalidades específicas de

PNUD-Costa Rica, Venciendo el temor, inseguridad ciudadana y desarrollo humano en Costa Rica, Informe Nacional de Desarrollo Humano, 2005, p. 2. 
vulnerabilidad -las ocasionadas por la violencia y el despojo- y a la protección de un núcleo esencial de derechos fundamentales de las personas. Seguridad ciudadana se entiende como la condición personal, objetiva (acaecimiento real de los hechos de violencia o despojo) y subjetiva (percepción de inseguridad -amenaza subjetiva-) de encontrarse libre de violencia o despojo intencional por parte de otros.

En general, los estudios de seguridad y deterioro se basan en la tasa de homicidios dolosos (delitos contra la vida) y de robos de viviendas (delito contra la propiedad), y esos índices pretenden medir el grado de violencia.

Estos índices de criminalidad han aumentado en nuestro país a lo largo de los últimos quince años. No obstante, estos factores deben ponerse en proporción, por considerarse que están debajo del resto de Latinoamérica.

No compartimos esa conclusión, pues el país ha cambiado. Existe una mayor cantidad de hechos delictivos graves como producto de la ausencia de medidas preventivas del Estado para solventarlos y del fracaso del Poder Judicial como ente represivo.

Una sociedad donde no se dé vigencia a la institucionalidad y donde los índices de desigualdad social se amplían, tiene como consecuencia inmediata el aumento de la criminalidad, con problemáticas de inseguridad ciudadana, como: delitos patrimoniales (sobre todo en lugares públicos y casas de habitación), cantidad de homicidios dolosos, violencia intrafamiliar, formas violentas de resolución de conflictos por acción privada (sicariato, amenazas, etc.), secuestros express, pandillas juveniles, control territorial en drogas, abusos policiales. Todas estas manifestaciones son potenciadas por la pobreza, exclusión social, desigualdad, marginación y, por supuesto, la incapacidad del Estado para brindar soluciones sociales oportunas.

No pretendemos extendernos más allá de lo necesario en este tema, pero conviene señalar cuáles han sido los factores de inseguridad:

i. Preventivos: se ha fracasado en políticas sociales y no se han instituido estrategias para la prevención del delito cometido por menores de edad. Se han aumentado las brechas de exclusión y desigualdad social.

ii. Represivos: no se han implementado políticas públicas para lograr la modernización y profesionalización de la policía (tanto administrativa como represiva). 
Por lo anterior, creemos que la respuesta a la seguridad humana y, por ende, a la seguridad ciudadana debe ser tratada integral y coordinadamente por el Estado (todos los ministerios: Educación, Salud, Deporte, Vivienda, Seguridad), con el fin de lograr la inclusión y la igualdad de oportunidades para los ciudadanos. Con ese propósito, es necesario posibilitar la participación de todos los actores sociales en la democracia, con vigencia de los derechos humanos e, incluso, reforzando los medios de control social informal, donde se fomenten los valores sociales y morales.

Sobre la eficacia policial en la prevención del delito, Waller plantea que el solo aumentar el número de policías asignados a labores policiales tradicionales incrementa el gasto y no reduce el delito, pero esto sí se consigue con la función policial orientada a los factores de riesgo (armas, por ejemplo), mediante una respuesta inteligente y eficaz en la prevención del delito. Por ello, como medio para reducir la criminalidad, este autor propone la debida gestión municipal, dirigida a determinar factores de riesgo, con una adecuada planificación para la prevención del delito, incrementando la inversión en programas de juventud en riesgo, talleres de violencia familiar, prevención de delincuencia en robos de vivienda en áreas críticas identificadas, con presencia policial y compromiso ciudadano. Según el mismo autor, esto podría lograrse por medio de la coalición entre la Policía, el gobierno local, los ministerios de Educación y Salud, grupos activos ciudadanos, etc. ${ }^{\text {. }}$

Ahora bien, el problema de inseguridad no debe enfocarse solo en el nivel preventivo, sino también desde el ámbito represivo. Así, la seguridad debe potenciarse con el fortalecimiento de la policía administrativa y judicial (profesionalización), además de una respuesta judicial oportuna, en cumplimiento del principio constitucional de tutela judicial efectiva ${ }^{9}$ y de justicia pronta y cumplida.

8 Así deducido del libro de WALLER (Irvin), Menos represión. Más seguridad, México D. F., Instituto Nacional de Ciencias Penales, 2007 (español).

9 "En la base de todo orden procesal está el principio y, con él, el derecho fundamental a la justicia, entendida como la existencia y disponibilidad de un sistema de administración de la justicia, valga decir, de un conjunto de mecanismos idóneos para el ejercicio de la función jurisdiccional del Estado —declarar el derecho controvertido o restablecer el violado, interpretándolo y aplicando imparcialmente en los casos concretos - lo cual comprende, a su vez, un conjunto de órganos judiciales independientes especializados en ese ejercicio, la disponibilidad de ese aparato para resolver los conflictos y corregir los entuertos que origina la vida social, en forma civilizada y eficaz, y el acceso garantizado a esa justicia para todas las personas, en condiciones de igualdad y sin discriminación". Lo anterior significa, en primer lugar, que el debido proceso exige la existencia, suficiencia y eficacia de un sistema judicial y procesal idóneo para 
La aplicación de un procedimiento expedito (respetuoso de las garantías constitucionales y legales, de conformidad con los derechos humanos), con el cual se resuelvan los conflictos por medio de un juicio justo, posibilita la confianza ciudadana en la Administración de Justicia.

La ciudadanía tiene una doble garantía con el procedimiento expedito: por una parte, la confianza ciudadana de un proceso ágil y oportuno al conflicto social; y por otro lado, la confianza de la persona acusada de recibir una respuesta estatal pronta y no someterse a un proceso criminal lento y desgastante.

Debemos recordar que el principio de tutela judicial efectiva forma parte de las garantías procesales de los sujetos. En palabras de Caro Coria, la tutela judicial efectiva se compone del libre acceso a la jurisdicción (entendido como el derecho que garantiza al individuo la posibilidad de acceder al proceso jurisdiccional), el libre acceso a las instancias (contar con recursos efectivos), una resolución fundada (motivada) y el derecho de efectividad (derecho de ejecución) $)^{10}$.

Por último, debe señalarse que no es cierto que en los procesos en flagrancia se juzgue la pobreza. Si bien un alto índice de individuos procesados por los delitos son personas con escasos recursos económicos, cualquier ciudadano puede ser acusado y juzgado mediante este mecanismo, en el tanto su detención sea flagrante. Pero, además, con el descongestionamiento de los tribunales de trámite ordinario se favorece una reacción estatal ágil y oportuna a delitos complejos o de difícil resolución.

garantizar el derecho fundamental a la justicia, que es la más importante manifestación del derecho de petición consagrado en la Constitución.

10 CARO CORIA, Dino Carlos. Las garantías constitucionales, Anuario de Derecho Constitucional Latinoamericano, año 12, tomo II, Programa Estado de Derecho para Sudamérica, 2006, pp. 1029-1032. 